\title{
Hubungan Antara Status Gizi Dengan Perkembangan Motorik Kasar Pada Balita
}

\author{
Arisda Candra Satriawati ${ }^{1)}$; Sitti Sarti ${ }^{2)}$, Puput Kurnia Sari ${ }^{3)}$ \\ 1) 2) 3) Fakultas Kesehatan, Universitas Wiraraja, Sumenep 69451, Indonesia \\ Corresponding Author: Arisda Candra Satriawati \\ E-mail: arisdacandra@gmail.com
}

\section{INFORMASI ARTIKEL \\ Riwayat Artikel: \\ Submit : 15-09-2021 \\ Revisi : 17-10-2021 \\ Diterima : 31-10-2021 \\ Publikasi : 30-11-2021 \\ DOI : \\ http://dx.doi.org/10.30587/ijmt.v1i1.3322}

\section{Keywords:}

Nutritional status;

Development;

Gross motor skills ;

Kata Kunci:

Status gizi;

Perkembangan;

Motorik kasar;

\begin{abstract}
Healthy toddlers (1-3 years old) will experience reasonable and normal development, according to the ability standards of children their age, while children with impaired nutritional status will experience obstacles in their development. This study aims to study the relationship nutritional status and gross motor development of toddler in ujung piring Village, Bangkalan Regency. The research method based on Cross Sectional where the population is all children aged 1-3 years as many as 80 children, while the sample taken is 45 people by simple random sampling. The data collection method used the standard deviation table and KPSP, with a cross tabulation table and tested with the Spearman rank test, with a significance level of $=0.05$. The results of the study, most of the nutritional status of toddler is good nutrition (55.6\%), most of the gross motor development of children is appropriate (64.4\%). From the results of the Spearman rank test, a significance value of $p=0.000$ $(p<a)$ was obtained, which means that there is a relationshipnutritional status and children's gross motor development. The results of this study can be concluded that there is a relationship between nutritional status and gross motor development of children. For this reason, it is expected that parents will care more about their children, provide nutritious food and provide appropriate stimulation so that the growth and development of children can be exceeded in accordance with expectations.
\end{abstract}




\section{PENDAHULUAN}

Pada lima tahun pertama kehidupan anak merupakan masa emas perkembangan, dan hal tersebut sangat mempengaruhi kemampuan belajar, kemampuan sosial, serta kemampuan emosional mereka. Perkembangan merupakan bertambahnya kemampuan fungsi tubuh (Susanto, 2011). Perkembangan anak terdiri dari perkembangan motorik kasar dan motorik halus; perkembangan sosialisasi dan kemandirian; serta perkembangan bicara dan Bahasa. Keempat aspek perkembangan tersebut harus selalu dalam pantauan orang tua. Ada beberapa faktor yang mempengaruhi perkembangan anak usia 1-5 tahun, diantaranya adalah faktor genetik dan faktor lingkungan yang berupa lingkungan biologis, fiisik, psikologi, dan lingkungan keluarga Perkembangan anak balita (Soetjiningsih, 2012).

Salah satu fase perkembangan anak yang penting adalah ketika anak berusia 1-3 tahun yang disebut dengan toodler. Anak usia toddler (1-3 tahun) akan mengalami perkembangan yang wajar dan normal yang sesuai dengan kemampuan pada anak seusianya. Akan tetapi, banyak pula terjadi kasus keterlambatan perkembangan anak. Ada sekitar 5 hingga 10\% anak yang diperkirakan mengalami terjadinya keterlambatan perkmebangan. Meskipun data angka kerjadian perkembangan pada anak ini tidak dilaporkan secara pasti,namun diperkirakan ada sekitar 1 hingga 3\% anak yang berusia 1-5 tahun telah mengalami keterlambatan perkembangan. Adapun aspek perkembangan yang sering mengalami gangguan adalah aspek motorik, bahasa, sosial-emosional, dan kognitif (Medise, 2013).

Salah satu indikator yang sangat penting untuk mengukur derajat kesehatan masyarakat adalah status gizi, khususnya status gizi pada anak usia 1 hingga 5 tahun dimana pada anak usia ini masih sangat membutuhkan asupan nutrisi yang adekuat untuk menunjang pertumbuhan dan perkembangan yang baik (Mulyani, Yunita, Mudlikah, \& Octaviyanti, 2021). Pada anak yang kurang gizi, akan mengakibatkan tubuhnya lemah sehingga tidak dapat melakukan aktivitas fisik dan pikiran sesuai dengan perkembangan anak usia toddler, khususnya perkembangan motorik kasar seperti; anak tidak dapat melompat dengan dua kaki, tidak dapat membangun beberapa kotak, sulit berinteraksi dengan orang lain dan sebagainya. Kekurangan gizi merupakan sepertiga dari penyebab terjadinya kematian anak di dunia. Berdasarkan data dari World Health Organization pada tahun 2015, ada sekitar 104 juta anak di dunia yang mengalami kurang gizi. Dari 36 negara-negara di dunia, Indonesia merupakan salah satu negara yang memberikan sumbangan masalah]h gizi sebanyak 90\% (UNICEF Indonesia, 2016).

Maryuni, et al. (2016) dalam penelitiannya di kelurahan Duren Sawit Jakarta timur dan desa Rumpit Bogor Jawa Barat pada anak usia 3-5 tahun menunjukkan bahwa semakin besar usia anak cenderung semakin menyimpang atau meragukan perkembangan motoriknya. Penyimpangan perkembangan motorik kasar pada anak usia 3 tahun sebesar $1,4 \%$, penyimpangan pada usia 4 tahun sebesar $1,2 \%$ dan pada anak usia 5 tahun sebesar $2,5 \%$. Dengan status gizi sangat pendek $3,9 \%$, pendek $15,1 \%$, normal $79,1 \%$ dan tinggi $2 \%$.

Berdasarkan data hasil PSG (Pemantauan Status Gizi) pada tahun 2019 di Desa Ujung Piring Bangkalan Kabupaten Bangkalan angka kejadian status gizi kurang sebesar $22.9 \%$, obesitas sebesar $15.7 \%$, dan yang gizi buruk (kurus sekali) ada $3.6 \%$, normalnya sebesar $57.8 \%$ (dari total 80 balita).

Tujuan penelitian ini adalah untuk mengetahui hubungan status gizi dengan perkembangan motorik kasar anak balita di Desa Ujung Piring Kabupaten Bangkalan. 


\section{METODE}

Jenis penelitian yang dilakukan merupakan penelitian analitik dengan desain penelitian Cross Sectional. Populasi dari penelitian ini adalah semua anak usia 1-3 tahun di Desa Ujung Piring Kabupaten Bangkalan sebanyak 80 anak (berdasarkan kohort balita bulan Agustus 2019). Teknik pengambilan sampel dengan proportional random sampling, jumlah sample sebanyak 45 balita.

Instrumen penelitian untuk variabel status gizi menggunakan antropometri sedangkan untuk variabel perkembangan motorik kasar menggunakan KPSP yang berbentuk pernyataan jenis dichotomous. Adapun tehnik analisa uji statistik yang digunakan yaitu analisa uji korelasi rank spearman dengan tingkat signifikansi $(\mathrm{a})=$ 0,05 .

\section{HASIL PENELITIAN}

\section{Data Umum}

Tabel 1. Distribusi Frekuensi Usia Ibu Di Desa Ujung Piring Kabupaten Bangkalan

\begin{tabular}{lcc}
\hline \multicolumn{1}{c}{ Usia ibu } & Frekuensi & Persentase (\%) \\
\hline$\leq 20$ tahun & 14 & 31,1 \\
20-35 tahun & 29 & 64,4 \\
$31-40$ tahun & 2 & 4,4 \\
\hline Total & 45 & 100,0
\end{tabular}

Sumber: Data primer, 2019

Tabel 1 menunjukkan bahwa sebagian besar ibu berusia antara 20-35 tahun yaitu sebanyak 29 orang $(64,4 \%)$.

Tabel 2. Distribusi Frekuensi Pendidikan Ibu Di Desa Ujung Piring Kabupaten Bangkalan

\begin{tabular}{lcc}
\hline \multicolumn{1}{c}{ Pendidikan } & Frekuensi & Persentase (\%) \\
\hline SD & 15 & 33,3 \\
SLTP & 15 & 33,3 \\
SLTA & 11 & 24,4 \\
PT/ Akademi & 4 & 8,9 \\
\hline Total & 45 & 100 \\
\hline \multicolumn{2}{l}{ Sumber: Data primer, 2019}
\end{tabular}

Tabel 2 menunjukkan bahwa sebagian besar pendidikan ibu adalah SD dan SLTP yaitu masing- masing sebanyak 15 orang $(33,3 \%)$.

Tabel 3 Distribusi Frekuensi Pekerjaan Ibu Di Desa Ujung Piring Kabupaten Bangkalan

\begin{tabular}{lcc}
\hline \multicolumn{1}{c}{ Pekerjaan } & Frekuensi & Persentase (\%) \\
\hline Tidak bekerja & 24 & 53,3 \\
Tani & 0 & 0,0 \\
Swasta & 13 & 28,9 \\
PNS & 8 & 17,8 \\
\hline Total & 45 & 100 \\
\hline
\end{tabular}

Sumber: Data primer, 2019

Tabel 3 menunjukkan bahwa sebagian besar ibu tidak bekerja yaitu sebanyak 24 orang $(53,3 \%)$.

Tabel 4. Distribusi Frekuensi Usia Anak Ibu Di Desa Ujung Piring Kabupaten Bangkalan

\begin{tabular}{ccc}
\hline Usia anak & Frekuensi & Persentase (\%) \\
\hline $1-2$ tahun & 22 & 48,9 \\
$2-3$ tahun & 23 & 51,1 \\
\hline Total & 45 & 100,0 \\
\hline Sumber: Data primer, 2019 &
\end{tabular}

Tabel 4 menunjukkan bahwa sebagian besar anak berusia 2-3 tahun yaitu sebanyak 23 orang $(51,1 \%)$.

Tabel 5. Distribusi Frekuensi Jenis Kelamin Anak Di Desa Ujung Piring Kabupaten Bangkalan

\begin{tabular}{lcc}
\hline Jenis kelamin anak & Frekuensi & Persentase (\%) \\
\hline Laki-laki & 18 & 40,0 \\
Perempuan & 27 & 60,0 \\
\hline Total & 45 & 100,0 \\
\hline
\end{tabular}

Sumber: Data primer, 2019

Tabel 5 menunjukkan bahwa sebagian besar anak berjenis kelamin perempuan yaitu sebanyak 27 orang $(60,0 \%)$.

Tabel 6. Distribusi Frekuensi Urutan Anak Di Desa Ujung Piring Kabupaten Bangkalan

\begin{tabular}{lcc}
\multicolumn{1}{c}{ Urutan anak } & Frekuensi & Persentase (\%) \\
\hline Anak ke 1 & 15 & 33,3 \\
Anak ke $2-4$ & 26 & 57,8 \\
Anak ke $>4$ & 4 & 8,9 \\
\hline Total & 45 & 100,0 \\
\hline Sumber: Data primer, 2019 &
\end{tabular}

Tabel 6 menunjukkan bahwa sebagian besar merupakan anak ke 2-4 yaitu sebanyak 26 orang $(57,8 \%)$. 
Tabel 7. Distribusi Frekuensi Status Gizi Di Desa Ujung Piring Kabupaten Bangkalan

\begin{tabular}{lcc}
\hline \multicolumn{1}{c}{ Status gizi } & Frekuensi & Persentase $(\%)$ \\
\hline Gizi lebih & 7 & 17,8 \\
Gizi baik & 24 & 51,2 \\
Gizi kurang & 13 & 28,8 \\
Gizi buruk & 1 & 2,2 \\
\hline Total & 45 & 100 \\
\hline
\end{tabular}

Sumber: Data primer, 2019

Tabel 7 menunjukkan bahwa sebagian besar status gizi anak adalah gizi baik yaitu sebanyak 23 orang $(51,2 \%)$.

Tabel 8. Distribusi Frekuensi Perkembangan Motorik Kasar Gizi Di Desa Ujung Piring

\begin{tabular}{lcc}
\hline $\begin{array}{c}\text { Perkembangan } \\
\text { motorik kasar }\end{array}$ & Frekuensi & $\begin{array}{c}\text { Persentase } \\
(\%)\end{array}$ \\
\hline Sesuai & 30 & 66,7 \\
Meragukan & 12 & 26,7 \\
Penyimpangan & 3 & 6,6 \\
\hline Total & 45 & 100,0 \\
\hline
\end{tabular}

Kabupaten Bangkalan

Sumber: Data primer, 2019

Tabel 8 didapatkan hasil bahwa sebagian besar perkembangan motorik kasar anak adalah sesuai yaitu sebanyak 30 orang $(66,7 \%)$.

Tabel 9. Hasil Tabulasi Silang Status Gizi Dengan Perkembangan Motorik Kasar Di Desa Ujung Piring Kabupaten Bangkalan

\begin{tabular}{ccccccccc}
\hline \multirow{2}{*}{$\begin{array}{c}\text { Status } \\
\text { gizi }\end{array}$} & \multicolumn{9}{c}{ Perkembangan motorik kasar } & \multirow{2}{*}{ Sesuai } & \multicolumn{3}{c}{ Meragukan } & \multicolumn{2}{l}{ Penyimpangan } & \\
\cline { 2 - 8 } & $\Sigma$ & $\%$ & $\Sigma$ & $\%$ & $\Sigma$ & $\%$ & $\Sigma$ & $\%$ \\
\hline Lebih & 5 & 11,1 & 1 & 2,2 & 1 & 2,2 & 7 & 100 \\
Baik & 23 & 51,1 & 1 & 2,2 & 0 & 0,0 & 24 & 100 \\
Kurang & 2 & 4,4 & 10 & 22,2 & 1 & 2,2 & 13 & 100 \\
Buruk & 0 & 0,0 & 0 & 0,0 & 1 & 2,2 & 1 & 100 \\
\hline Total & 30 & 66,7 & 12 & 26,7 & 3 & 6,6 & 5 & 100 \\
\hline & Uji Rank Spearmaan & & & \multicolumn{5}{c}{$\mathrm{p}=0,000$} \\
\hline
\end{tabular}

Sumber: Data primer, 2019

Dari tabel 9 menunjukkan bahwa dari 7 anak dengan status gizi lebih didapatkan perkembangan motorik kasar anak yang sesuai sebanyak 5 anak $(11,1 \%)$ sedangkan yang meragukan sebanyak 1 anak (2,2\%) dan yang mengalami penyimpangan sebanyak 1 anak (2,2\%), dari 24 anak dengan status gizi baik didapatkan perkembangan motorik kasar anak yang sesuai sebanyak 23 anak (51,1\%) sedangkan yang meragukan sebanyak 1 anak $(2,2 \%)$ dan tidak ada yang mengalami penyimpangan, dari 13 anak dengan status gizi kurang didapatkan perkembangan motorik kasar anak yang sesuai sebanyak 2 anak $(4,4 \%)$ sedangkan yang meragukan sebanyak 10 anak $(22,2 \%)$ dan yang mengalami penyimpangan sebanyak 1 anak (2,2\%), dan dari 1 anak dengan status gizi buruk didapatkan perkembangan motorik kasar anak mengalami penyimpangan (2,2\%). Hasil Uji Rank Spearman didapatkan nilai kemaknaan $\mathrm{p}=0,000$ karena $\mathrm{p}<\mathrm{a}$ $(0,000<0,05)$ yang berarti Ho ditolak, hal ini menunjukkan bahwa ada hubungan antara status gizi dengan perkembangan motorik kasar anak usia 1-3 tahun.

\section{PEMBAHASAN}

Dari hasil penelitian didapatkan bahwa sebagian besar anak termasuk dalam gizi baik dan ada yang mengalami gizi lebih. Banyaknya anak yang mengalami gizi baik dan bahkan ada yang mengalami gizi lebih bisa dikarenakan ibu mengetahui macam-macam makanan bergizi sehingga memberikan makanan yang bergizi pada anaknya, dengan demikian asupan gizi anak dapat terpenuhi (adekuat). Menurut Sutrisno YM, (2014), faktor yang mempengaruhi perkembangan motorik kasar anak digolongkan atas faktor herediter, hormonal dan lingkungan. Faktor lingkungan antara lain faktor gizi, pola asuh, cuaca dan status kesehatan.

Selain itu didapatkan ada anak yang mengalami gizi kurang dan gizi buruk. Hal ini bisa disebabkan oleh karena biasanya anak tidak suka makan sayur dan buah-buahan sehingga zat gizi yang bisa didapat dari sayur dan buah-buahan tidak dapat diberikan pada anak, akibatnya anak menjadi berstatus gizi kurang. Adanya anak toddler yang mengalami gizi buruk dikarenakan rendahnya tingkat pendidikan ibu sehingga tidak dapat memberikan variasi menu bergizi untuk 
anaknya, akibatnya anak mendapat asupan gizi yang kurang beragam sehingga ada beberapa zat gizi yang tidak didapat oleh anak. Selain itu juga disebabkan karena tingkat ekonomi yang rendah sehingga keluarga tidak dapat menyediakan berbagai macam makanan yang bergizi bagi anak. Juga bisa dikarenakan kebiasaan di masyarakat yang menganggap anak yang lebih muda memerlukan makanan lebih sedikit dibandingkan yang lebih tua sehingga orang tua tidak memperhatikan kalau anaknya mengalami kurang gizi.

Dari hasil penelitian sebagian besar adalah anak ke 2-4 dan bahkan ada yang merupakan anak ke 5 atau lebih Menurut Suhardo (2008), anak yang paling rawan mengalami kekurangan gizi adalah anak-anak yang tumbuh di dalam suatu keluarga yang tergolong miskim. Diantara seluruh anak dalam anggota keluarga, anak bungsulah yang biasanya paling terpengaruh dalam hal kondisi kekurangan pangan. Para orang tua umumnya tidak menyadari bahwa anak yang berusia sangat muda justru membutuhkan pangan yang relatif lebih banyak daripada anak-anak yang usianya lebih tua, rendahnya pemahaman ini menyababkan anak-anak yang lebih muda justru cenderung tidak diberikan cukup makan oleh orang tuanya, mereka diberikan porsi yang lebih sedikit dengan kandungan gizi yang lebih sedikit pula. mendapatkan asupan makanan yang lebih sedikit dibandingkan dengan yang lebih tua. Tahun-tahun awal masa kanak-kanak yang biasanya meliputi satu hingga enam tahun, adalah yang paling rawan. Kurang gizi akan sedikit dijumpai bila jumlah anggota keluarganya lebih kecil.

Chindy Gabriella Wauran, Rina Kundre (2016) dalam penelitiannya menyimpulkan bahwa status gizi mempengaruhi perkembangan motorik kasar anak, sehingga untuk mendapatkan perkembangan motorik yang sesuai memerlukan kecukupan gizi yang optimal sehingga pemantauan status gizi dan perkembangan motorik anak dapat dilakukan secara berkala. Sejalan dengan hasil penelitian Musniati, (2017) bahwa ada hubungan status gizi dengan perkembangan motorik kasar, personal sosial, motorik halus, dan bahasa pada anak usia 1-3 tahun (Toddler).

Hasil penelitian menunjukkan bahwa sebagian besar perkembangan motorik kasar anak adalah sesuai. Anak dapat menyelesaikan tahap perkembangannya dengan normal dikarenakan adanya stimulasi dari orang tua agar anak dapat berkembang sesuai dengan tahapan perkembangannya. Orang tua dapat menstimulasi dikarenakan ia tidak bekerja sehingga mempunyai banyak waktu untuk menstimulasi perkembangan anak. Selain itu kecukupan gizi juga mempengaruhi perkembangan motorik kasar pada balita. Status gizi yang baik akan mempengaruhi kemampuan sistem syaraf pusat untuk membuat dan melepaskan neurotransmiter sehingga kemampuan anak akan sejalan dengan umur (Choirunnisa. dkk., 2013).

Penelitian ini menunjukkan bahwa dari 7 anak dengan status gizi lebih didapatkan perkembangan motorik kasar anak yang sesuai sebanyak 5 anak $(11,1 \%)$ sedangkan yang meragukan sebanyak 1 anak (2,2\%) dan yang mengalami penyimpangan sebanyak 1 anak (2,2\%), dari 24 anak dengan status gizi baik didapatkan perkembangan motorik kasar anak yang sesuai sebanyak 23 anak (51,1\%) sedangkan yang meragukan sebanyak 1 anak $(2,2 \%)$ dan tidak ada yang mengalami penyimpangan, dari 13 anak dengan status gizi kurang didapatkan perkembangan motorik kasar anak yang sesuai sebanyak 2 anak $(4,4 \%)$ sedangkan yang meragukan sebanyak 10 anak $(22,2 \%)$ dan yang mengalami penyimpangan sebanyak 1 anak (2,2\%), dan dari 1 anak dengan status gizi buruk didapatkan perkembangan motorik kasar anak mengalami penyimpangan $(2,2 \%)$. Perkembangan anak usia toddler yang sesuai lebih banyak pada anak dengan gizi baik. Hasil Uji Rank Spearman menunjukkan bahwa ada hubungan antara status gizi dengan 
perkembangan motorik kasar anak usia 1-3 tahun dengan nilai kemaknaan $p=0,000$ yang berarti Ho ditolak.

Hasil penelitian ini sejalan dengan hasil penelitian Lindawati (2013) yang menyebutkan bahwa ada hubungan antara status gizi dengan perkembangan motorik kasar. Penelitian ini juga mendukung penelitian (Ratna Suhartini1, Haniarti2, 2018) yang mendapatkan hasil adanya hubungan antara status gizi dengan perkembangan motorik kasar pada balita.

Masa balita merupakan masa penting dalam tahap tumbuh kembang, asupan gizi dan stimulasi yang baik akan mempengaruhi perkembangan anak selanjutnya. Status gizi yang baik akan membuat proses tumbuh kembang balita menjadi semakin optimal. Didukung dengan stimulasi orang tua terhadap anak akan lebih meningkatkan proses perkembangan motorik kasarnya. Jika status gizi kurang atau bahkan buruk, maka perkembangan dan pertumbuhan balita juga akan terhambat. Perkembangan motorik kasarnya akan terhambat karena balita tidak punya cukup energi dan mudah sakit sehingga untuk perkembangan dan pertumbuhan menjadi terganggu.

\section{SIMPULAN}

Berdasarkan hasil penelitian dapat disimpulkan bahwa Ada hubungan antara status gizi dengan perkembangan motorik kasar balita Di Desa Ujung Piring Kabupaten Bangkalan.

Berdasarkan hasil kesimpulan, disarankan orang tua lebih peduli pada anak, memberikan makanan yang bergizi serta memberikan stimulasi yang sesuai sehingga pertumbuhan dan perkembangan anak dapat terlewati sesuai dengan harapan.

Diharapkan bagi petugas posyandu mengetahui tentang status gizi anak termasuk perkembangan motorik kasarnya sehingga dapat memberikan penyuluhan kepada masyarakat karena masa balita merupakan masa yang penting bagi perkembangan anak selanjutnya, sehingga diperlukan kurikulum yang dapat meningkatkan pertumbuhan dan perkembangan anak menjadi lebih optimal. Perkembangan anak tidak terlepas dari berbagai faktor yang mempengaruhi lainnya selain status gizi, sehingga diharapkan pada penelitian mendatang peneliti lain dapat meneliti faktor-faktor yang mempengaruhi perkembangan anak lainnya

\section{DAFTAR PUSTAKA}

Chindy Gabriella Wauran, Rina Kundre, W. S. (2016). Hubungan Status Gizi Dengan Perkembangan Motorik Kasar Pada Anak Usia 1-3 Tahun di Kelurahan Bitung Kecamatan Amurang Kabupaten Minahasa Selatan. Jurnal Keperawatan, 4 no 2.

Choirunnisa. dkk. (2013). Hubungan antara Status Gizi dengan Perkembangan Motorik Kasar Anak Balita di RSUD Tugurejo Semarang. Skripsi. STIKES Telogorejo Semarang.

Lindawati. (2013). Faktor-faktor yang Berhubungan dengan Perkembangan Motorik Anak Usia Pra Sekolah. Jurnal. Jakarta: Jurusan Keperawatan Poltekkes Kemenkes Jakarta I.

Maryuni. dkk. (2016). Hubungan antara Perkembangan Motorik Anak Usia 3 -5 Tahun dengan Status Gizi (Tb/U) Berdasarkan Tingkat Pendidikan Ibutle. Jurnal Gizi Volume (2):6.

Medise, B. E. (2013). Seputar Kesehatan Anak. Retrieved from www.idai.or.id

Mulyani, E., Yunita, N., Mudlikah, S., \& Octaviyanti, D. (2021). Internal and External Factors That Influence Development of Childrens Independence. 585, 518-522.Proceeding UMGESHIC 2020. Atlantic Press. 
MUSNIATI, Y. (2017). Hubungan Status Gizi Dengan Perkembangan Motorik Kasar, Motorik Halus, Personal Sosial, dan Bahasa Pada Anak Usia 1-3 Tahun (Toddler). Skripsi. Universitas Hasanuddin. http://digilib.unhas.ac.id

Ratna Suhartini1, Haniarti2, M. M. (2018). Hubungan Status Gizi Dengan Perkembangan Motorikkasar Anak Umur 13 Tahun di Posyandu Bunga Cengkeh Desa Puncak Harapan Kecamatan Maiwa. Jurnal Ilmiah Manusia Dan Kesehatan, 1.

Soetjiningsih. (2012). Tumbuh Kembang Anak. Jakarta: EGC.

Suhardo. (2008). Perencanaan Pangan dan Gizi. Jakarta: Bumi Aksara.

Susanto, A. (2011). Perkembangan Anak Usia Dini: Pengantar dalam Berbagai Aspeknya. Jakarta: Prenada Media Group.

Sutrisno YM. (2014). Hubungan Status Gizi dengan Perkembangan Motorik Kasar anak usia 6-24 bulan di Posyandu desa Pari Kecamatan Mandala kabupaten Pandeglang provinsi Banten. Universitas Islam Negeri Syarif Hidayatullah Jakarta.

UNICEF INDONESIA. (2016). Status Gizi Anak. www.unicef.org 